\title{
Skeletal muscle mitochondrial uncoupling prevents diabetes but not obesity in NZO mice, a model for polygenic diabesity
}

\author{
Anja Voigt ${ }^{1} \cdot$ Yvonne Katterle $^{1} \cdot$ Melanie Kahle $^{1} \cdot$ Reinhart Kluge $^{1} \cdot$ \\ Annette Schürmann ${ }^{1,2} \cdot$ Hans-Georg Joost ${ }^{1,2} \cdot$ Susanne Klaus ${ }^{1}$
}

Received: 13 August 2015/Accepted: 4 November 2015/Published online: 19 November 2015

(c) Springer-Verlag Berlin Heidelberg 2015

\begin{abstract}
Induction of skeletal muscle (SM) mitochondrial stress by expression of uncoupling protein 1 (UCP1) in mice results in a healthy metabolic phenotype associated with increased secretion of FGF21 from SM. Here, we investigated whether SM mitochondrial uncoupling can compensate obesity and insulin resistance in the NZO mouse, a polygenic diabesity model. Male NZO mice were crossed with heterozygous UCP1 transgenic (tg) mice (mixed C57BL/6/CBA background) and further backcrossed to obtain $\mathrm{F} 1$ and N2 offspring with 50 and $75 \%$ NZO background, respectively. Male F1 and N2 progeny were fed a high-fat diet ad libitum for 20 weeks from weaning. Blood glucose was reduced, and diabetes (severe hyperglycemia $>300 \mathrm{mg} / \mathrm{dl}$ ) was fully prevented in both F1- and N2-tg progeny compared to a diabetes prevalence of $15 \%$ in $\mathrm{F} 1$ and $42 \%$ in N2 wild type. In contrast, relative body fat content and plasma insulin were decreased, and glucose tolerance was improved, in F1-tg only. Both F1 and N2-tg showed decreased lean body mass. Accordingly, induction of SM stress response including FGF21 expression and secretion was similar in both F1 and N2-tg mice. In white adipose tissue, expression of FGF21 target genes was enhanced in F1 and N2-tg mice, whereas lipid metabolism genes were induced in F1-tg only. There was no evidence for induction of browning in either UCP1 backcross. We conclude that SM mitochondrial uncoupling induces FGF21 expression and prevents diabetes in mice
\end{abstract}

Susanne Klaus

klaus@dife.de

1 German Institute of Human Nutrition in Potsdam, ArthurScheunert-Allee 114-116, 14558 Nuthetal, Germany

2 German Center for Diabetes Research (DZD), Neuherberg, Germany with a 50-75\% NZO background independent of its effects on adipose tissue.

Keywords Polygenic obesity - Skeletal muscle . Uncoupling protein 1 . Fibroblast growth factor 21 . Diabetes - White adipose tissue - Body composition . Glucose tolerance test - Gene expression · Lipid metabolism - Glucose metabolism

\section{Introduction}

Ectopic expression of uncoupling protein 1 (UCP1) in skeletal muscle has been shown to result in a phenotype characterized by increased energy expenditure, reduced body weight, reduced fat mass, improved glucose tolerance, decreased muscle energy efficiency, and altered substrate oxidation (Couplan et al. 2002; Klaus et al. 2005; Li et al. 2000). UCP1-tg mice express the murine UCP1 gene in striated skeletal muscle, driven by the human skeletal actin promoter (Klaus et al. 2005). We have shown previously that UCP1-tg mice display a healthy metabolic phenotype and increased longevity. They are protected from the development of insulin resistance independent of the diet, displaying a dissociation of obesity and insulin resistance (Keipert et al. 2011; Neschen et al. 2008). Also, they show substantially improved in vivo insulin action due to an increased substrate flux through the glycolytic pathway paralleled by increased insulin-stimulated glucose uptake and increased substrate oxidation in SM (Keipert et al. 2013a; Neschen et al. 2008; Ost et al. 2014). Overall, UCP1 expression in skeletal muscle thus leads to beneficial effects on glucose homeostasis. This healthy metabolic phenotype of UCP1-tg mice is associated with the 
induction and secretion of fibroblast growth factor 21 (FGF21) from skeletal muscle (Keipert et al. 2014) which in turn linked to a metabolic remodeling program in skeletal muscle due to muscle mitohormesis (Ost et al. 2015). Overexpression and systemic administration of FGF21 has been shown to reduce obesity and improve glucose homeostatic in mice (Coskun et al. 2008; Inagaki et al. 2008; Kharitonenkov et al. 2005; Zhang et al. 2012). Thus, FGF21 is considered a potential therapeutic in obesity, diabetes and related disorders (Kharitonenkov and Adams 2014). Circulating FGF21 is largely increased In UCP1-tg mice and exerts endocrine effects mainly on white adipose tissue (WAT) such as a recruitment of inducible brown adipocytes (also termed "browning" of WAT) (Bartelt and Heeren 2014) characterized by increased mitochondrial content, UCP1 expression, and metabolic activity (Keipert et al. 2014). Interestingly, skeletal muscle expression of UCP1 delayed the development of diet-induced obesity and insulin resistance, thereby antagonizing the life-shortening effects of high-fat diets (Keipert et al. 2011). Expression of UCP1 in skeletal muscle was able to reduce body weight and improve glucose homeostasis in a monogenetic model of obesity, the lethal yellow $\left(\mathrm{A}^{\mathrm{y} / \mathrm{a})}\right.$ mice (Bernal-Mizrachi et al. 2002), but it is not known if it might also alleviate diabetes and obesity in a polygenic model such as the New Zealand obese (NZO) mice. These mice develop the metabolic syndrome and type 2 diabetes with beta-cell loss (Joost 2010). NZO mice originate from a colony of agouti mice selected for obesity which was subsequently fixed by inbreeding (Bielschowsky and Goodall 1970). NZO mice have been used in outcross studies aimed to locate genes responsible for obesity, insulin resistance and diabetes (Joost 2010; Joost and Schurmann 2014; Leiter et al. 1998). Quantitative trait loci (QTLs) affecting adiposity and blood glucose have been identified on a number of chromosomes and different loci (Plum et al. 2002; Taylor et al. 2001; Vogel et al. 2009, 2012, 2013) confirming the polygenic nature of obesity and diabetes development in this mouse model. On a high-fat diet NZO mice exhibit hypertension and hypercholesterolemia in addition to obesity, hyperinsulinemia and hyperglycemia (Joost and Schurmann 2014; Ortlepp et al. 2000). The development of obesity in NZO mice was found to be caused by hyperphagia combined with reduced energy expenditure and impaired voluntary physical activity (Jurgens et al. 2006). Development of diabetes and beta-cell failure in NZO mice is linked to the development of obesity and is also dependent on the presence of dietary carbohydrates (Jurgens et al. 2007; Kluth et al. 2011). In order to investigate if the disturbed glucose homeostasis and/or obesity of NZO mice can be rescued by skeletal muscle uncoupling, we crossed UCP1- tg mice with NZO mice and investigated body composition, glucose homeostasis, and gene expression in muscle and WAT in male offspring of the $\mathrm{F} 1$ progeny $(50 \%$ NZO background) and N2 progeny (75\% NZO background) challenged by a high-fat diet. The results show that the mitochondrial stress-induced remodeling of skeletal muscle including induction of FGF21 as a myokine is preserved in mice with increasing NZO background. These effects of the UCP1 transgene were associated with the prevention of diabetes and changes in body composition but not with a significant reduction of adiposity.

\section{Materials and methods}

\section{Animal maintenance and backcross setup}

All analyses were performed in male mice. Mice were maintained at $22{ }^{\circ} \mathrm{C}$ and a $12 \mathrm{~h}: 12 \mathrm{~h}$ dark/light cycle with food and water provided ad libitum. Animal experiments were performed in compliance with the German animal protection law (TierSchG). The mice were housed and handled in accordance with good animal practice as defined by FELASA (www.felasa.eu/guidelines.php) and the national animal welfare body GV-SOLAS (www.gv-solas. de/index.html). The animal welfare committees of the DIfE as well as the local authorities (Landesamt für Umwelt, Gesundheit und Verbraucherschutz, Brandenburg) approved all animal experiments. To obtain F1 progeny, female heterogeneous UCP1-tg transgenic mice (on a mixed C57BL/6/CBA background, obtained as described (Klaus et al. 2005) were crossed with male NZO mice obtained from our own breeding colony (NZO/HIBom: Dr. R. Kluge, German Institute of Human Nutrition, Nuthetal, Germany). Female, transgenic F1-tg mice were backcrossed once more with male NZO mice to obtain the N2 progeny with $75 \%$ NZO genetic background. Mice were genotyped for expression of the HSA-mUCP1 transgene as described (Klaus et al. 2005). Our backcross setup was chosen in a way to minimize possible prenatal maternal effects on the offspring since we used only male NZO mice for the backcross.

\section{Experimental set up}

Experiments were performed in male $\mathrm{F} 1$ and $\mathrm{N} 2$ offspring comparing wild-type (WT) and transgenic animals (UCP1). From weaning on at 4 weeks of age mice were fed ad libitum a commercial high-fat diet (Altromin C1057, Lage, Germany) containing $15 \%$ fat (w/w) with an energy content of $18.7 \mathrm{~kJ} / \mathrm{g}$ as determined by bomb calorimetry. In F1 wild type (F1-wt) and UCP1 transgenic mice (F1-tg) body 
composition was determined weekly and mice were subjected to a glucose tolerance test at 20 weeks of age. Random, non-fasting blood glucose from tail blood was determined several times during the experiment between 8 and 9 a.m. Animals were killed at 23 weeks of age. N2 wild-type (N2-wt) and UCP1 transgenic mice (N2-tg) were treated similarly with the only difference that glucose tolerance tests were performed in week 16 and animals killed in week 20. Mice were killed in the morning under isoflurane anesthesia, $2 \mathrm{~h}$ after food withdrawal. Tissues and organs were snap frozen in liquid nitrogen after dissection and stored at $-80^{\circ} \mathrm{C}$ until further analyses.

\section{Body composition and body length}

Body composition was determined weekly using quantitative magnetic resonance (QMR) (Brukeŕs Minispec MQ10, Houston, TX, USA) as described (Klaus et al. 2005). Lean body mass was calculated by subtracting body fat values obtained by QMR from body weight obtained by weighing prior to QMR measurement. Body length was determined as nose to anus length in anaesthetized animals at time of killing.

\section{Glucose tolerance test}

Glucose tolerance tests were performed in week 20 (F1) or week $16(\mathrm{~N} 2)$ after $16 \mathrm{~h}$ of fasting. Glucose $(2 \mathrm{mg} / \mathrm{g}$ body weight) was injected intraperitoneal, and tail blood samples were obtained before, as well as $15,30,60,120$, and $240 \mathrm{~min}$ after glucose injection for determination of blood glucose using a blood glucose sensor (Ascendia Elite, Bayer, Leverkusen). Approximately $20 \mu \mathrm{l}$ blood per sample was obtained additionally, centrifuged and plasma frozen for subsequent analysis of insulin by ELISA as described (Neschen et al. 2008). Homeostasis model assessment index (HOMA) for insulin resistance was calculated as described (Lansang et al. 2001).

\section{Plasma and biochemical analysis}

Free fatty acids (Wako NEFA C Kit, Wako Chemicals, Neuss, Germany), total cholesterol (Wako CHOL-H L-Type R1/R2 Chemicals, Neuss, Germany), and triglycerides (triglyceride and free glycerol reagent, SIGMA, Germany) were analyzed in triplicates on 96-well plates as described (Noatsch et al. 2011). Insulin was analyzed by an ultrasensitive ELISA assay (Insulin mouse ultrasensitive ELISA, DRG Instruments GmbH, Germany). FGF21 (Mouse/Rat FGF-21 Quantikine ELISA Kit; R\&D Systems) and IGF1 (Mouse/Rat IGF-I Quantikine ELISA Kit; R\&D Systems) values were determined by ELISA. All measurements were taken according to the instructions of the manufacturers.

\section{Gene expression analysis}

RNA isolation and quantitative real-time PCR (qPCR) was performed as described (Keipert et al. 2013b). Quadriceps and gastrocnemius combined were used for SM, and epididymal WAT (eWAT) for adipose tissue gene expression analysis. Tissue-specific gene expression was calculated as $\Delta \Delta C_{\mathrm{T}}$ using beta-actin or beta-2 microglobulin (B2M) for normalization and expressed relative to the F1-wt group which was normalized to a value of 1 .

\section{Statistical analysis}

Data are expressed as mean \pm SEM. Statistical analysis war performed using SPSS 14.0 or GraphPad Prism 5. Two-tailed Student's $t$ tests were performed to compare WT and TG mice. Body composition development as well as glucose tolerance tests were analyzed by repeated measure factorial ANOVA. Differences in diabetes prevalence were assessed using Chi-squared test. Differences of $p<0.05$ were considered significant.

\section{Results}

\section{Body weight and composition}

In the $\mathrm{F} 1$ progeny, transgenic mice (F1-tg) had a markedly reduced body weight compared to wild type (F1-wt) (Fig. 1a) which resulted from decreased lean body mass (Fig. 1b) as well as decreased absolute and relative body fat content (Fig. 1c; Table 1). Final body weight, lean mass and fat mass of F1-tg were reduced by 18, 7.3, and $10.6 \mathrm{~g}$, respectively, compared to F1-wt. Because F1-tg mice also showed a reduced body length (Table 1), BMI was calculated to correct for body size. BMI was also significantly decreased in F1-tg compared to F1-wt mice (Table 1). Relative body fat content was similar at the start of high-fat feeding but increased to a higher extent in F1-wt mice (Fig. 1b) resulting in significantly higher percentage of body fat in F1-wt at 23 weeks of age (Table 1).

Mice of the N2 generation (75\% NZO genetic background) were overall heavier than F1 progeny and body weight as well as BMI of N2-wt mice was significantly higher than that of N2-tg mice throughout the experiment (Fig. 1d; Table 1). This was partly due to a consistently decreased lean body mass in N2-tg mice (Fig. 1e). Although numerical values of absolute and relative body fat mass content were also decreased in N2-tg mice, this did not reach statistical significance (Fig. 1f; Table 1). Because of the high individual variations, a larger number of animal would be required to clearly rule out a protective effect of SM UCP1 expression regarding obesity 
Fig. 1 Development of body composition in F1 (a-c) and N2 (d-f) NZO backcross wild type (wt, open symbols) and UCP1 transgenic (tg) mice (filled symbols) fed a high-fat diet from weaning on. Data are mean \pm SE. $n=20-21$ for F1 and $10-12$ for N2. Differences between the groups were assessed by factorial ANOVA for repeated measurements
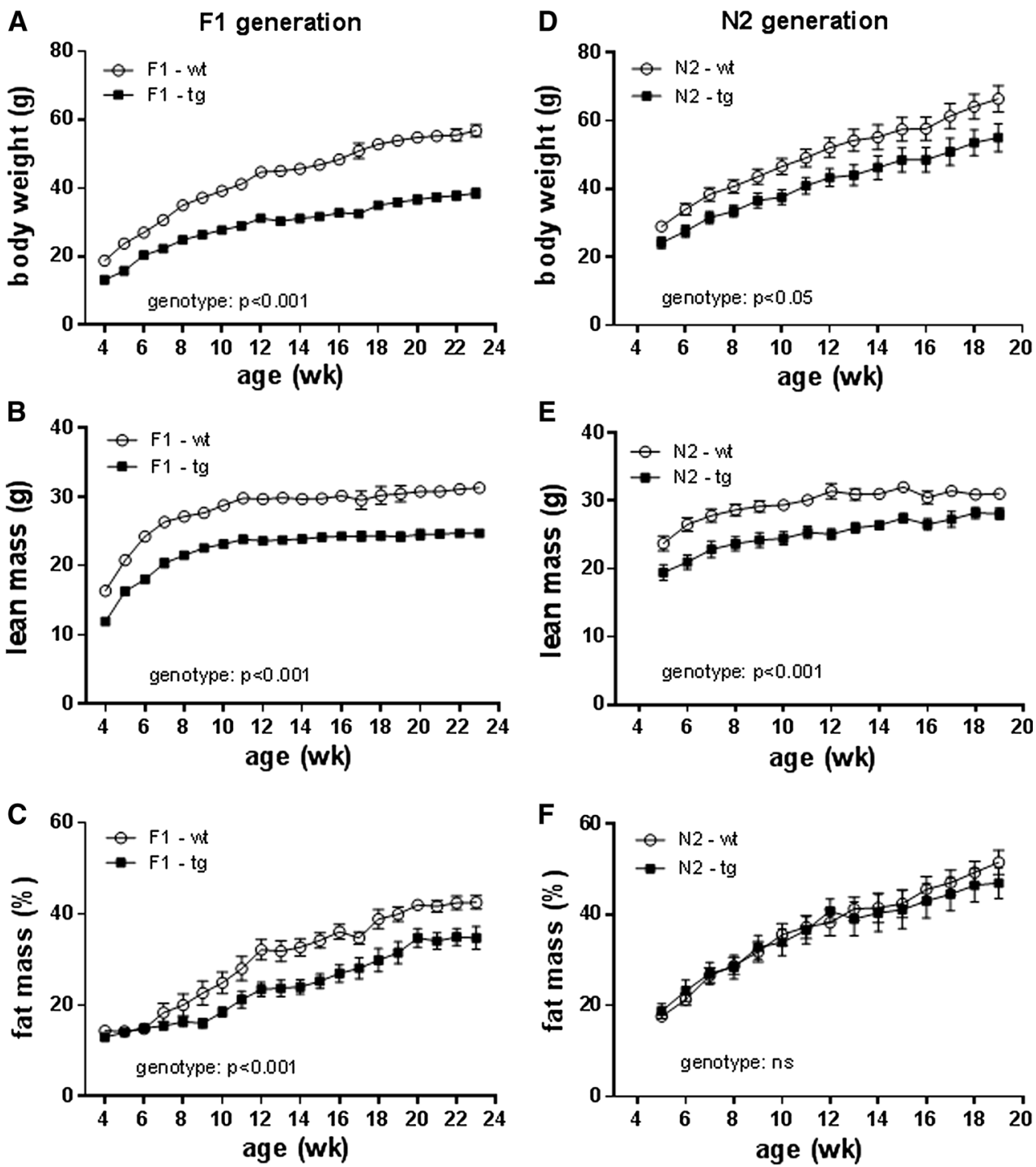

development. Body length differences disappeared in N2 mice consistent with similar levels of circulating IGF-1 (Table 1). Relative liver weights did not differ between wt and tg mice.

F1-tg mice showed a significantly improved glucose tolerance compared to F1-wt (Fig. 2a) with a lower and earlier glucose peak and a rapid subsequent drop in blood glucose. Area under the curve was also significantly lower [563 \pm 31 arbitrary units (a.u.)] compared to F1-wt (856 \pm 65 a.u., $p<0.001)$. Insulin levels during glucose tolerance test were significantly lower in F1-tg mice compared to F1-wt (Fig. 2b). F1-tg mice also showed significantly decreased blood glucose, plasma insulin and plasma free fatty acids compared to F1-wt. No significant differences were observed in plasma triglycerides (Table 1). Random blood glucose levels over $300 \mathrm{mg} / \mathrm{dl}$ $(16.6 \mathrm{mM})$ were observed in wt mice only (Fig. 1e), and mice exceeding this threshold at any time were defined as diabetic. Diabetes prevalence was $15 \%$ in F1-wt in line with a reduced HOMA index in F1-tg compared to F1-wt (Table 1).

In the N2 generation glucose response during GTT was very similar in wt and tg mice (Fig. 2c). Interestingly, although average plasma insulin levels during GTT were similar to those observed in F1, there were no more statistically significant differences due to high individual variability in both N2-wt and N2-tg mice. However, fed and fasted blood glucose concentrations were still significantly decreased in N2-tg mice compared to N2-wt (Fig. 2e; Table 1), resulting in a $50 \%$ decrease of HOMA index that failed to reach statistical significance ( $p=0.067)$ due to the large individual differences. However, despite these large individual variations, N2-tg mice still did not show any incidence of diabetes, whereas the prevalence in N2-wt mice was $42 \%$ (Fig. 2e; Table 1). Curiously, N2 mice had overall lower plasma TG levels 
Table 1 Body composition and plasma parameters of F1 and N2 NZO backcross wild type (wt) and UCP1 transgenic (tg) mice fed a high-fat diet from weaning

\begin{tabular}{|c|c|c|c|c|}
\hline & F1-wt & F1-tg & $\mathrm{N} 2$-wt & $\mathrm{N} 2-\operatorname{tg}$ \\
\hline Body weight $(\mathrm{g})$ & $56.0 \pm 1.6(20)$ & $38.5 \pm 1.2^{* * *}(21)$ & $66.4 \pm 3.9(12)$ & $55.1 \pm 4.1(10)$ \\
\hline Lean mass (g) & $31.8 \pm 0.4(20)$ & $24.5 \pm 0.3^{* * *}(21)$ & $31.1 \pm 0.5(12)$ & $28.1 \pm 0.9 * *(10)$ \\
\hline Lean mass $(\%)$ & $56.9 \pm 1.3(20)$ & $64.5 \pm 1.7 * *(21)$ & $48.5 \pm 2.7(12)$ & $53.1 \pm 3.4(10)$ \\
\hline Fat mass $(\mathrm{g})$ & $24.9 \pm 1.5(20)$ & $14.3 \pm 1.2^{* * *}(21)$ & $35.3 \pm 3.7(12)$ & $27.1 \pm 3.5(10)$ \\
\hline Fat mass $(\%)$ & $43.3 \pm 1.3(20)$ & $35.7 \pm 1.7 * *(21)$ & $51.6 \pm 2.7(12)$ & $47.0 \pm 3.4(10)$ \\
\hline Body length (cm) & $11.6 \pm 0.05(24)$ & $11.1 \pm 0.05^{* * *}(26)$ & $11.7 \pm 0.2(12)$ & $11.6 \pm 0.1(10)$ \\
\hline BMI $\left(\mathrm{kg} / \mathrm{m}^{2}\right)$ & $4.18 \pm 0.10(19)$ & $3.12 \pm 0.08 * * *(21)$ & $4.92 \pm 0.21(12)$ & $4.22 \pm 0.24 *(10)$ \\
\hline Liver weight (\%) & $4.03 \pm 0.12(20)$ & $4.32 \pm 0.11(21)$ & $4.07 \pm 0.14(12)$ & $4.26 \pm 0.22(10)$ \\
\hline Diabetes prevalence & $15 \%(22)$ & $0 \% *(20)$ & $42 \%(12)$ & $0 \% *(10)$ \\
\hline Random blood glucose (mg/dl) & $204.4 \pm 30(22)$ & $116.6 \pm 3 * *(20)$ & $286 \pm 35(12)$ & $172 \pm 17 * *(10)$ \\
\hline Random insulin (ng/ml) & $21.9 \pm 3.8(11)$ & $7.5 \pm 1.9^{* * *}(20)$ & $32.0 \pm 11.9(10)$ & $21.7 \pm 9.0(8)$ \\
\hline Fasting blood glucose (mg/dl) & $89.2 \pm 9.9(9)$ & $60.8 \pm 3.3 * *(11)$ & $122 \pm 9.2(10)$ & $88 \pm 9.0^{* *}(8)$ \\
\hline Fasting insulin (ng/ml) & $2.08 \pm 0.18(9)$ & $1.16 \pm 0.11 * * *(11)$ & $2.34 \pm 0.62(10)$ & $1.61 \pm 0.40(8)$ \\
\hline HOMA index & $11.7 \pm 2.1(9)$ & $4.4 \pm 0.6^{* *}(11)$ & $20.5 \pm 6.9(10)$ & $9.5 \pm 3.1(8)$ \\
\hline Plasma TG $(\mu \mathrm{g} / \mathrm{ml})$ & $830 \pm 105(25)$ & $938 \pm 85(26)$ & $586 \pm 92(12)$ & $764 \pm 92(10)$ \\
\hline Plasma FFA (mM) & $1.21 \pm 0.21(25)$ & $0.64 \pm 0.09 *(26)$ & $0.93 \pm 0.15(12)$ & $1.03 \pm 0.23(10)$ \\
\hline Plasma IGF1 (ng/ml) & n.d. & n.d. & $564 \pm 32(8)$ & $509 \pm 26(8)$ \\
\hline
\end{tabular}

Data are from 23 weeks (F1) or 19 weeks (N2) old mice except fasted blood glucose, fasted insulin and HOMA index which were obtained in week $20(\mathrm{~F} 1)$ or $16(\mathrm{~N} 2)$. Diabetes was defined as random blood glucose levels $>300 \mathrm{mg} / \mathrm{dl}$. All data are mean \pm SEM with $n$-number in parentheses

n.d. not determined

$* p<0.05 ; * * p<0.01 ; * * * p<0.001$ compared to wt of the same generation

than F1 which could be due to the fact that they were 4 weeks younger. Individual variations were very high also in F1 generation, probably because mice were not fasted.

Circulating FGF21 levels were more than doubled in N2-tg mice compared to N2-wt (Fig. 1f), suggesting that effects of mitochondrial stress on skeletal muscle were not antagonized by the NZO genetic background. Gene expression analysis of skeletal muscle confirmed the induction of UCP1 and FGF21 in skeletal muscle of UCP1$\operatorname{tg}$ mice which was even more pronounced in the $\mathrm{N} 2$ than in the F1 generation (Fig. 3). This was due to lower UCP1 gene expression in N2-wt [mean RQ-PCR cycle threshold $\left(C_{\mathrm{T}}\right)$ of 30.05] than in F1-wt (mean $C_{\mathrm{T}}$ of 28.12), whereas UCP1 expression levels were similar in both F1-tg and N2$\operatorname{tg}$ (mean $C_{\mathrm{T}}$ of 22.45 and 22.39 , respectively).

In SM of N2-tg mice there was a significantly increased expression of activating transcription factor 4 (Atf4) and C/EBP homologous protein (Chop, also known as DNAdamage inducible transcript 3 (Ddit3)), two transcription factors which are part of the integrated stress response (ISR) (Marciniak and Ron 2006), as well as glucose transporter 1 (Glut1, gene name Slc2a1). There were no expression changes of glucose transporter 4 (Glut4, gene name Slc2a4), cluster of differentiation $36(\mathrm{Cd} 36)$ or phosphoenolpyruvat-carboxykinase (Pck1) in either F1-tg or N2-tg mice. Expression of phosphoserine aminotransferase 1 (Psat1) and methylenetetrahydrofolate dehydrogenase (Mthfd2) was highly induced in both F1 and N2-tg mice (Fig. 3). These are two key genes of the serine, onecarbon, glycine (SOG) pathway which is induced by SM mitochondrial stress (Ost et al. 2015). UCP1 expression in SM has been shown to induce a fiber type switch from glycolytic type II fibers toward oxidative type I fibers (Couplan et al. 2002; Ost et al. 2014). In accordance, expression of myosin heavy polypeptide 7 , cardiac muscle, beta (Myh7) encoding a myosin found in cardiac muscle and in type I skeletal muscle fibers was highly increased in increased in both F1 and N2-tg mice. Myh1 and Myh4, encoding skeletal muscle myosin heavy polypeptide 1 and 4 (markers of IIx and IIb fibers, respectively), showed no expression differences.

Analysis of gene expression in WAT as a major target of FGF21 is shown in Fig. 4. Overall gene expression changes induced by SM UCP1 expression were largely attenuated in the N2 generation. Expression of FGF receptor 1 (Fgfr1) and its co-receptor $\beta$-Klotho (Klb) was increased in F1-tg mice as well as genes of lipid metabolism such as fatty acid synthase (Fasn), acetyl-CoA carboxylase alpha (Acaca), stearoyl-CoA desaturase 1 ( $\mathrm{Scd} 1)$, and hormone sensitive lipase (Lipe). In addition, expression of the adipokines 
Fig. 2 Glucose homeostasis and plasma FGF21 in F1 and N2 NZO backcross wild type (wt) and UCP1 transgenic (tg) mice fed a high-fat diet from weaning until week 23 (F1-generation) or week 20 (N2-generation). Blood glucose levels and plasma insulin during glucose tolerance test performed in week 20 in F1 generation $(\mathbf{a}, \mathbf{b} ; n=7-8)$ and week 16 in $\mathrm{N} 2$ generation $(\mathbf{c}, \mathbf{d}$; $n=8-10)$. e Highest individual random blood glucose levels achieved during HFD feeding period $(n=10-22)$. f FGF21 plasma levels of $\mathrm{N} 2 \mathrm{wt}$ and $\mathrm{tg}$ mice at 20 weeks of age $(n=8)$. Data are mean \pm SE. $* p<0.05 ; * * p<0.01$; $* * * p<0.001$ compared to $\mathrm{wt}$
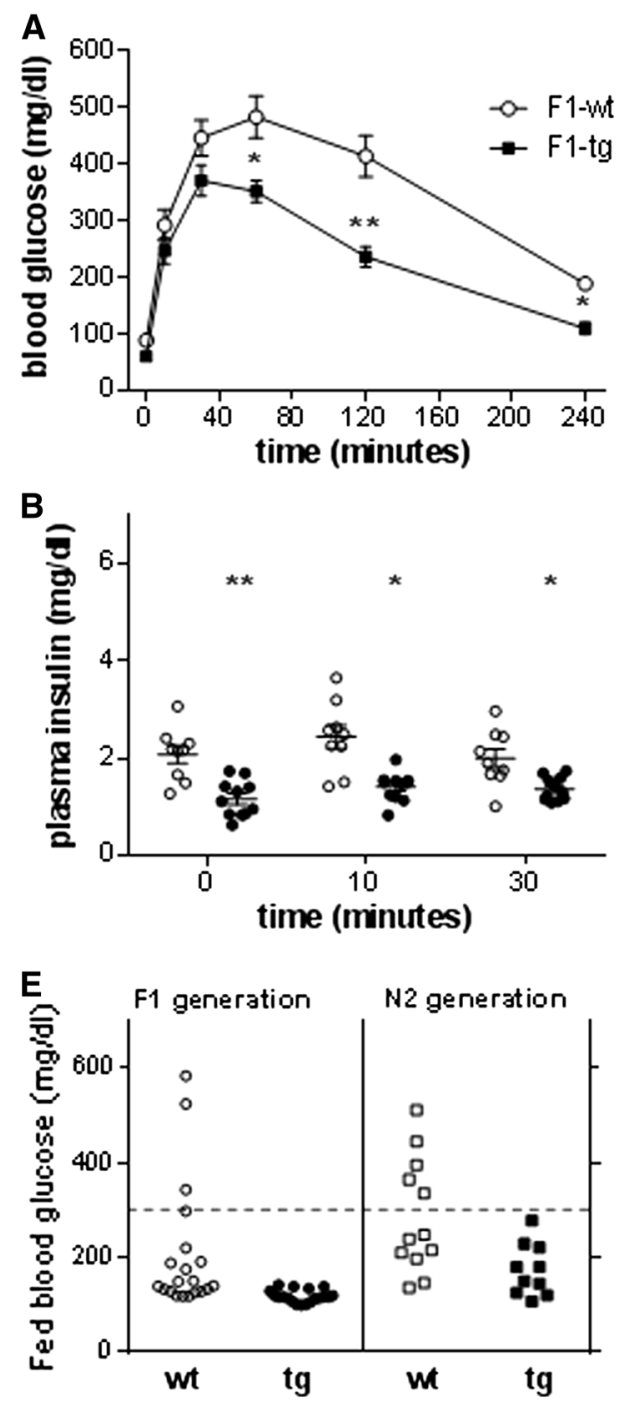
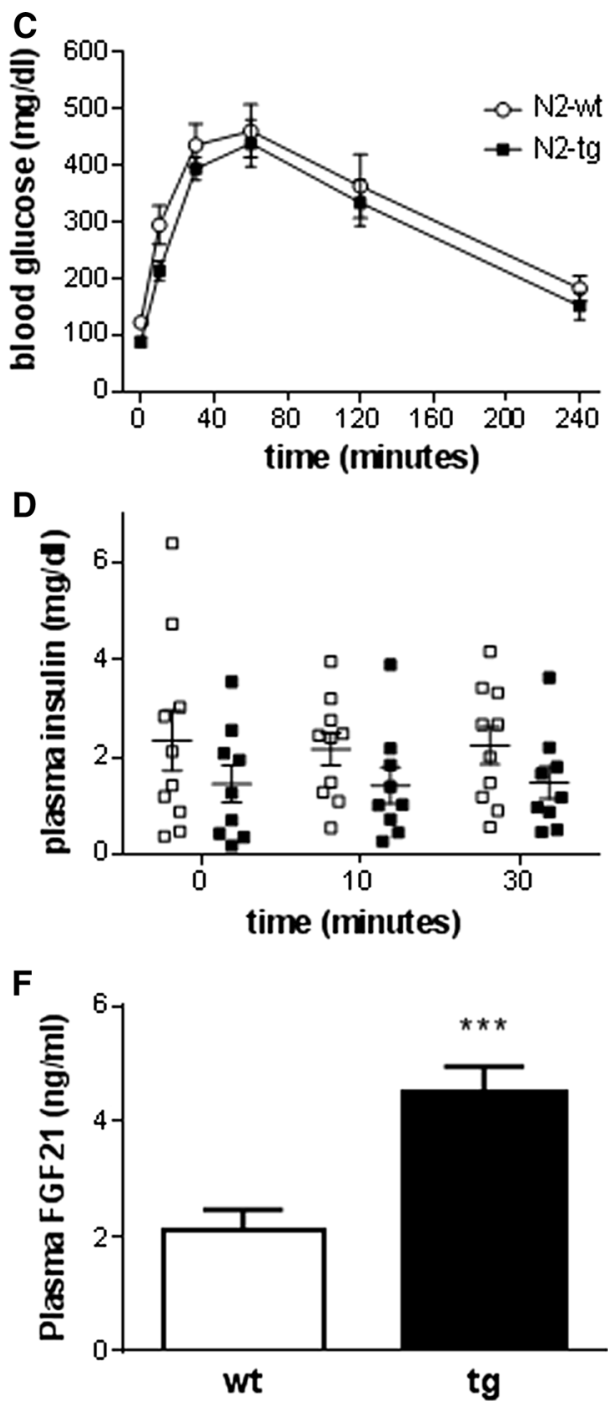

adiponectin (Adipoq) and retinol-binding protein 4 (Rbp4) were induced. UCP1 and the transcriptional co-activator peroxisome proliferator-activated receptor gamma coactivator 1-alpha (PGC1 $\alpha$, gene name Ppargc1a) as markers for brown adipocyte were not induced in either F1 or N2-tg mice which is in contrast to findings in UCP1-tg mice on a B16 background (Keipert et al. 2014). Furthermore, no expression changes were observed in leptin (Lep) and mesoderm specific transcript (Mest) which have recently been established as predictive biomarkers of adipose tissue expansion (Voigt et al. 2015). With regard to glucose metabolism, there were no expression changes in insulin receptor (Insr), and Glut1, whereas Glut4 and Pck1 gene expression was induced in both F1 and N2-tg compared to wt. Overall, gene expression changes induced by SM UCP1 expression were considerably attenuated in the N2 generation. The remaining significant expression changes (Klb, Fasn, Rbp4, Glut4, and Pck1) were much less pronounced in N2-tg than in F1-tg mice (Fig. 4).

\section{Discussion}

Modifier genes can have a large impact on the phenotypical penetrance and expressivity of traits inherited in a simple Mendelian fashion (Nadeau 2001). Body size and thus body weight are highly heritable traits but possibly influenced by up to 6000 genes (Reed et al. 2008). It has also repeatedly been shown that the genetic background can influence the development of obesity and insulin resistance. Leptin deficiency in mice for example leads to multiple metabolic abnormalities including obesity, insulin resistance, reduced fertility and body temperature while the severity of these traits is strongly affected by the genetic background (Ewart-Toland et al. 1999; Haluzik et al. 2004; Qiu et al. 2001). The NZO mouse is a model for polygenic "diabesity" that shows obesity-associated insulin resistance, beta-cell failure, and ultimately chronic hyperglycemia leading to the development of type 2 diabetes thus closely resembling the human metabolic syndrome. 
Fig. 3 Skeletal muscle gene expression in $\mathrm{F} 1$ (a) and $\mathrm{N} 2$ (b) NZO backcross wild type (wt, open bars) and UCP1 transgenic (tg, black bars) mice fed a high-fat diet from weaning until week 23 (F1-generation) or week 20 (N2-generation).

$n=8-10$. Data are mean \pm SE $* p<0.05 ; * * p<0.01$;

$* * * p<0.001$ compared to wt which were set as 1
A

F1 generation muscle

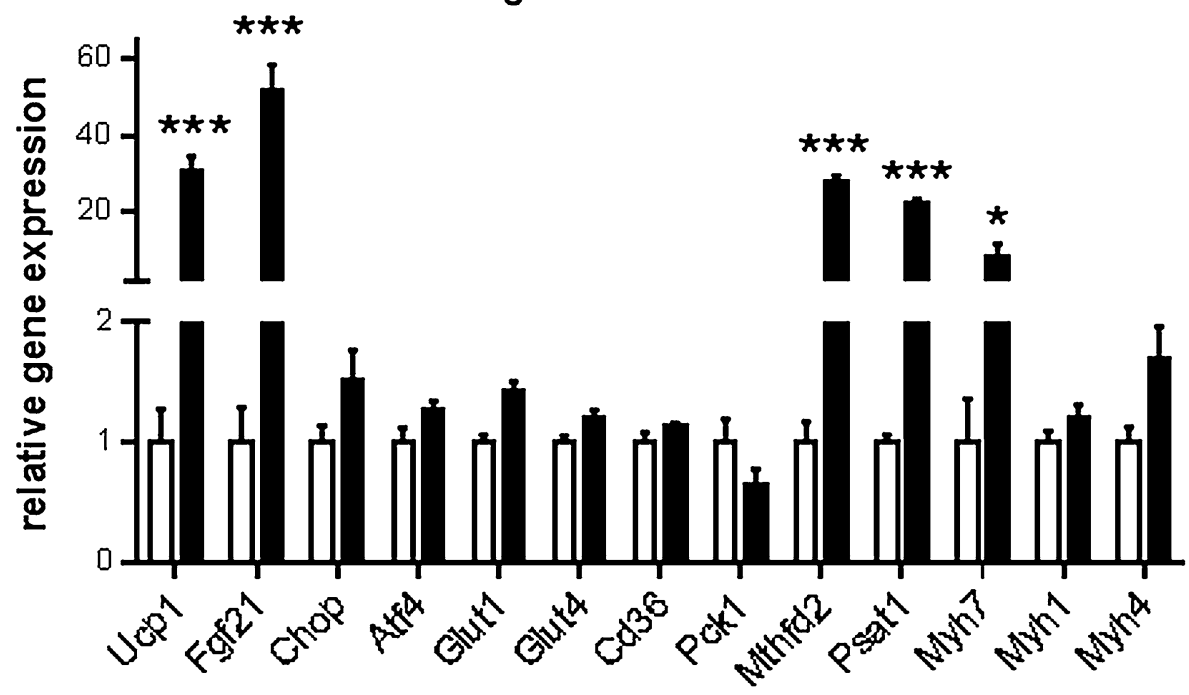

B

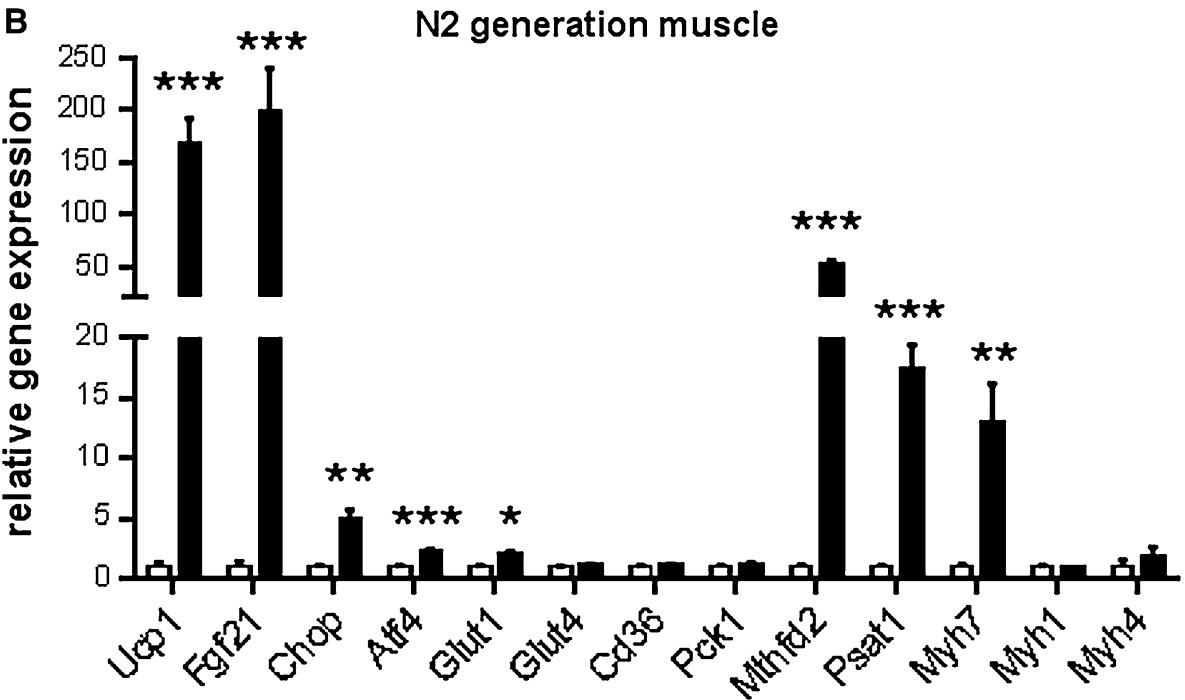

Investigations of the genetic basis of metabolic syndrome pathogenesis in this model lead to the identification of a number of adipogenic and diabetogenic gene variants which altogether suggest that fat oxidation and fat storage are crucial determinants of obesity and diabetes (Joost and Schurmann 2014). Skeletal muscle mitochondrial uncoupling profoundly affects substrate metabolism not only of muscle itself but also of other tissues such as WAT, leading to an overall improved glucose homoeostasis (Katterle et al. 2008; Keipert et al. 2011; Neschen et al. 2008). This is apparently still the case on the NZO polygenic diabetes and obesity background. NZO mice show a high incidence of obesity especially on high-fat diets, and it has been shown previously that the diabetes prevalence on a high-fat diet decreased from over $90 \%$ in male mice of NZO background to $17 \%$ a NZO $\times$ C57BL/6J intercross (Vogel et al. 2009). This is comparable with the diabetes prevalence of $15 \%$ that we observed in the F1-wt and confirms that NZO-derived diabetes is markedly suppressed by the genetic background of lean, diabetes-resistant mice such as C57BL/6J. Diabetes prevalence was more than doubled in N2-wt with $75 \%$ NZO background corroborating the strong effect of the NZO genome on high-fat-diet-induced hyperglycemia. Skeletal muscle UCP1 expression completely abolished the occurrence of severe hyperglycemia in both the $\mathrm{F} 1$ and $\mathrm{N} 2$ progeny which is supported by significantly lower fasted and random blood glucose levels in tg mice. Although HOMA index in the N2-tg was not significantly different from $\mathrm{N} 2-\mathrm{wt}$ due to high individual variations, this still suggests an increased insulin sensitivity in transgenic mice which is persistent even on a $75 \% \mathrm{NZO}$ genetic background.

The development of diabetes in N2-wt seems to be linked to an increased early adiposity in the affected mice. All five N2-wt mice developing diabetes showed over $21 \%$ body fat already at 12 weeks of age. On the other 
Fig. 4 White adipose tissue (eWAT) gene expression in F1 (a) and N2 (b) NZO backcross wild type (wt, open bars) and UCP1 transgenic mice (tg, black bars) fed a high-fat diet from weaning until week 23 (F1generation) or week 20 (N2generation). $n=8-11$. Data are mean \pm SE. $* p<0.05$ $* * p<0.01 ; * * * p<0.001$ compared to wt which were set as 1
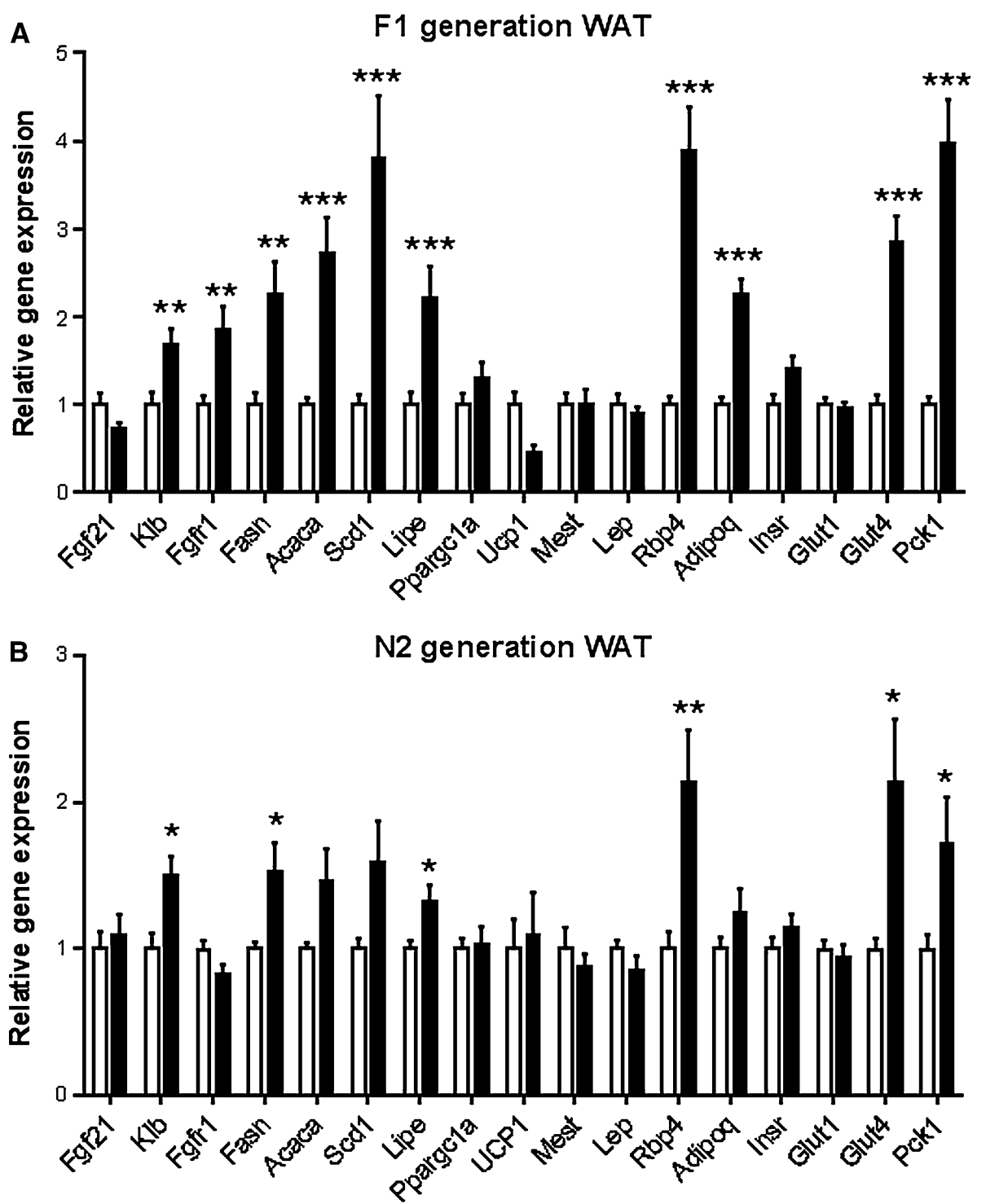

hand, at this age $50 \%$ of the N2-tg progeny also showed a relative body fat content above $21 \%$ without developing diabetes. The prevention of diabetes development by skeletal muscle mitochondrial uncoupling is thus not due to the reduction of adiposity below the threshold necessary for diabetes development. This confirms that UCP1 expression in skeletal muscle leads to a dissociation of adiposity and impaired glucose homeostasis as shown before (Katterle et al. 2008; Keipert et al. 2013a) which is apparently independent of the genetic background.

Compared to C57BL/6J mice as reference strain, the genome of NZO mice contains over four million single nucleotide polymorphisms (SNPs) of which approximately 200,000 are specific to NZO when compared to other mouse strains (Keane et al. 2011). Using outcross populations of NZO mice, several variants have been identified in genes that are associated with different adipogenic and diabetogenic traits such as food intake, fat accumulation, and insulin levels (Joost and Schurmann 2014) in genes such as Pctp (Pan et al. 2006a, b), Tbc1d1 (Chadt et al. 2008), Zfp69 (Scherneck et al. 2009), and Ifi202b (Vogel et al. 2012). The activity of phosphatidylcholine transfer protein (Pctp) which is reduced in NZO mice is associated with serum insulin levels making this an interesting candidate to investigate in further studies.

Mitochondrial dysfunction has been implicated in the development of insulin resistance, but it is still unclear if there is a causal relationship (Montgomery and Turner 2015), and recently it has been suggested that rather an increase in mitochondrial efficiency precedes the development of insulin resistance as shown in a rat model of high-fat diet feeding (Crescenzo et al. 2014). It is interesting to note that an uncoupling induced decrease in mitochondrial efficiency (Neschen et al. 2008) in turn leads to a protection from diabetes development. Skeletal muscle mitochondrial uncoupling has profound effects on skeletal 
muscle energy metabolism evident by a fiber type switch toward oxidative type 1 fibers (Couplan et al. 2002; Ost et al. 2014). This was preserved also with increasing NZO genetic background which could possibly account for the decreased lean body mass to which muscle contributes to a great extent. Furthermore, SM mitochondrial uncoupling induces a metabolic remodeling as a result of compensatory stress-signaling network that preserves cellular function as part of a muscle mitohormesis program (Keipert et al. 2013a; Ost et al. 2015). The induction of key genes linked to this remodeling was not attenuated but rather increased in N2-tg mice compared to F1-tg mice showing clearly that the normal response to skeletal muscle mitochondrial uncoupling is preserved in mice with increasing NZO genetic background. Part of the mitochondrial stress response induced in UCP1-tg mice is a massive induction of FGF21 expression and secretion from skeletal muscle leading to over fivefold increased circulating FGF21 levels (Keipert et al. 2014). Skeletal muscle FGF21 expression was completely preserved in F1 and N2tg progeny resulting in elevated FGF21 plasma levels which in N2-tg mice were very similar to those previously reported in UCP1-tg mice (Keipert et al. 2014). FGF21 plasma levels are known to be increased in diet-induced obesity as shown in different mouse models as well as humans (Iglesias et al. 2012). FGF21 plasma levels of N2tg mice on a high-fat diet were indeed similar to those observed in wt mice on a C57BL/6/CBA background fed a high-fat diet (Keipert et al. 2014). Induction of FGF21 in obesity is likely a compensatory response because FGF21 has been shown to have numerous beneficial metabolic effects. Systemic administration and overexpression of FGF21 was shown to reduce diet induced as well as genetic obesity, and FGF21 is now considered to have promising therapeutic potential (Ohta and Itoh 2014). By studying lipodystrophic mice (Veniant et al. 2012) or mice with fatspecific deletion of the FGF receptor FGFR1 (Adams et al. 2012), it was shown that adipose tissue is the key tissue for the majority of the FGF21-dependent metabolic effects by binding of FGF21 to the FGFR1-KLB complex (Luo and McKeehan 2013). The high-fat-diet-induced increase in FGF21 is thought to be linked to a FGF21 resistance as evident by an attenuation of FGF21 effects on liver and adipocytes (Fisher et al. 2010). It was suggested that this could be due to an inflammation induced repression of KLB expression in adipocytes (Diaz-Delfin et al. 2012). We found that KLB gene expression was rather increased than decreased in WAT of F1 and N2-tg mice which is not supportive of a FGF21 resistance at the level of WAT with increasing NZO genetic background. The expression of genes which are crucial for adipocyte function is regulated by numerous factors besides FGF21 and examination of downstream FGF21 signaling would be necessary to elucidate if impairment at this level could be causally linked to the attenuation of SM mitochondrial uncoupling induced WAT changes with increasing NZO background. Remarkable is the complete lack of browning in WAT even of F1-tg mice which is likely due to the NZO background which should be addressed in future studies. On a C57BL/ 6/CBA background we have observed the recruitment of brown adipocytes in epididymal WAT of UCP1-tg mice evidenced by an increased respiratory capacity and induction of brown fat marker genes such as UCP1 and PGC1 $\alpha$ (Keipert et al. 2014). It is generally accepted that FGF21 induces this browning (Eckardt et al. 2014; Poher et al. 2015) which was also confirmed in UCP1-tg mice (Keipert et al. 2014). Recruitable brown adipocytes within typical WAT depots [also named "brite", "beige" or "inducible brown adipocytes" (Harms and Seale 2013; Petrovic et al. 2010; Schulz et al. 2011)] were shown to be thermogenically functional (Shabalina et al. 2013) and associated with improved metabolic profiles (Bartelt and Heeren 2014). On the other hand, most metabolic effects of pharmacological FGF21 administration do not require the presence of UCP1 as recently reported in two studies using UCP1 knockout mice (Samms et al. 2015; Veniant et al. 2015) which is in line with our findings.

In conclusion, this study shows that the induction of mild mitochondrial stress in skeletal muscle and the subsequent increase in circulating FGF21 are not able to completely abolish the development of diet-induced obesity but fully prevent the development of diabetes in a polygenic diabesity model. WAT remodeling was attenuated with increased NZO genetic background which could possibly antagonize the FGF21 response at the level of WAT.

Acknowledgments The skillful technical assistance of Antje Sylvester and Andrea Teichmann is gratefully acknowledged. The study was supported by grants from the European Union's Seventh Framework Program FP7 2007-2013 under Grant Agreement No. 244995 (BIOCLAIMS Project), from the German Ministry of Education and Research (DZD, 01GI0922 and 01GI0925), and the State of Brandenburg.

\section{Compliance with ethical standards}

Conflict of interest All authors declare that they have no conflict of interests.

Animal rights All institutional and national guidelines for the care and use of laboratory animals were followed.

\section{References}

Adams AC, Yang C, Coskun T, Cheng CC, Gimeno RE, Luo Y, Kharitonenkov A (2012) The breadth of FGF21's metabolic actions are governed by FGFR1 in adipose tissue. Mol Metab $2: 31-37$ 
Bartelt A, Heeren J (2014) Adipose tissue browning and metabolic health. Nat Rev Endocrinol 10:24-36

Bernal-Mizrachi C, Weng S, Li B, Nolte LA, Feng C, Coleman T, Holloszy JO, Semenkovich CF (2002) Respiratory uncoupling lowers blood pressure through a leptin-dependent mechanism in genetically obese mice. Arterioscler Thromb Vasc Biol 22:961-968

Bielschowsky M, Goodall CM (1970) Origin of inbred NZ mouse strains. Cancer Res 30:834-836

Chadt A, Leicht K, Deshmukh A, Jiang LQ, Scherneck S, Bernhardt U, Dreja T, Vogel H, Schmolz K, Kluge R, Zierath JR, Hultschig C, Hoeben RC, Schurmann A, Joost HG, Al-Hasani H (2008) Tbc1d1 mutation in lean mouse strain confers leanness and protects from diet-induced obesity. Nat Genet 40:1354-1359

Coskun T, Bina HA, Schneider MA, Dunbar JD, Hu CC, Chen Y, Moller DE, Kharitonenkov A (2008) Fibroblast growth factor 21 corrects obesity in mice. Endocrinology 149:6018-6027

Couplan E, Gelly C, Goubern M, Fleury C, Quesson B, Silberberg M, Thiaudiere E, Mateo P, Lonchampt M, Levens N, De Montrion C, Ortmann S, Klaus S, Gonzalez-Barroso MD, Cassard-Doulcier AM, Ricquier D, Bigard AX, Diolez P, Bouillaud F (2002) High level of uncoupling protein 1 expression in muscle of transgenic mice selectively affects muscles at rest and decreases their IIb fiber content. J Biol Chem 277:43079-43088

Crescenzo R, Bianco F, Mazzoli A, Giacco A, Liverini G, Iossa S (2014) Mitochondrial efficiency and insulin resistance. Front Physiol 5:512

Diaz-Delfin J, Hondares E, Iglesias R, Giralt M, Caelles C, Villarroya F (2012) TNF-alpha represses beta-Klotho expression and impairs FGF21 action in adipose cells: involvement of JNK1 in the FGF21 pathway. Endocrinology 153:4238-4245

Eckardt K, Gorgens SW, Raschke S, Eckel J (2014) Myokines in insulin resistance and type 2 diabetes. Diabetologia 57:1087-1099

Ewart-Toland A, Mounzih K, Qiu J, Chehab FF (1999) Effect of the genetic background on the reproduction of leptin-deficient obese mice. Endocrinology 140:732-738

Fisher FM, Chui PC, Antonellis PJ, Bina HA, Kharitonenkov A, Flier JS, Maratos-Flier E (2010) Obesity is a fibroblast growth factor 21 (FGF21)-resistant state. Diabetes 59:2781-2789

Haluzik M, Colombo C, Gavrilova O, Chua S, Wolf N, Chen M, Stannard B, Dietz KR, Le Roith D, Reitman ML (2004) Genetic background $(\mathrm{C} 57 \mathrm{BL} / 6 \mathrm{~J}$ versus $\mathrm{FVB} / \mathrm{N})$ strongly influences the severity of diabetes and insulin resistance in ob/ob mice. Endocrinology 145:3258-3264

Harms M, Seale P (2013) Brown and beige fat: development, function and therapeutic potential. Nat Med 19:1252-1263

Iglesias P, Selgas R, Romero S, Diez JJ (2012) Biological role, clinical significance, and therapeutic possibilities of the recently discovered metabolic hormone fibroblastic growth factor 21. Eur J Endocrinol 167:301-309

Inagaki T, Lin VY, Goetz R, Mohammadi M, Mangelsdorf DJ, Kliewer SA (2008) Inhibition of growth hormone signaling by the fasting-induced hormone FGF21. Cell Metab 8:77-83

Joost HG (2010) The genetic basis of obesity and type 2 diabetes: lessons from the New Zealand obese mouse, a polygenic model of the metabolic syndrome. Results Probl Cell Differ 52:1-11

Joost HG, Schurmann A (2014) The genetic basis of obesityassociated type 2 diabetes (diabesity) in polygenic mouse models. Mamm Genome 25:401-412

Jurgens HS, Schurmann A, Kluge R, Ortmann S, Klaus S, Joost HG, Tschop MH (2006) Hyperphagia, lower body temperature, and reduced running wheel activity precede development of morbid obesity in New Zealand obese mice. Physiol Genomics 25:234-241
Jurgens HS, Neschen S, Ortmann S, Scherneck S, Schmolz K, Schuler G, Schmidt S, Bluher M, Klaus S, Perez-Tilve D, Tschop MH, Schurmann A, Joost HG (2007) Development of diabetes in obese, insulin-resistant mice: essential role of dietary carbohydrate in beta cell destruction. Diabetologia 50:1481-1489

Katterle Y, Keipert S, Hof J, Klaus S (2008) Dissociation of obesity and insulin resistance in transgenic mice with skeletal muscle expression of uncoupling protein 1. Physiol Genomics 32:352-359

Keane TM, Goodstadt L, Danecek P, White MA, Wong K, Yalcin B, Heger A, Agam A, Slater G, Goodson M, Furlotte NA, Eskin E, Nellaker C, Whitley H, Cleak J, Janowitz D, Hernandez-Pliego P, Edwards A, Belgard TG, Oliver PL, McIntyre RE, Bhomra A, Nicod J, Gan X, Yuan W, van der Weyden L, Steward CA, Bala S, Stalker J, Mott R, Durbin R, Jackson IJ, Czechanski A, Guerra-Assuncao JA, Donahue LR, Reinholdt LG, Payseur BA, Ponting CP, Birney E, Flint J, Adams DJ (2011) Mouse genomic variation and its effect on phenotypes and gene regulation. Nature 477:289-294

Keipert S, Voigt A, Klaus S (2011) Dietary effects on body composition, glucose metabolism, and longevity are modulated by skeletal muscle mitochondrial uncoupling in mice. Aging Cell 10:122-136

Keipert S, Ost M, Chadt A, Voigt A, Ayala V, Portero-Otin M, Pamplona R, Al-Hasani H, Klaus S (2013) Skeletal muscle uncoupling-induced longevity in mice is linked to increased substrate metabolism and induction of the endogenous antioxidant defense system. Am J Physiol Endocrinol Metab 304:E495-E506

Keipert S, Ost M, Chadt A, Voigt A, Ayala V, Portero-Otin M, Pamplona R, Al-Hasani H, Klaus S (2013b) Skeletal muscle uncoupling-induced longevity in mice is linked to increased substrate metabolism and induction of the endogenous antioxidant defense system. Am J Physiol Endocrinol Metab 304:E495-506

Keipert S, Ost M, Johann K, Imber F, Jastroch M, van Schothorst EM, Keijer J, Klaus S (2014) Skeletal muscle mitochondrial uncoupling drives endocrine cross-talk through the induction of FGF21 as a myokine. Am J Physiol Endocrinol Metab 306:E469-E482

Kharitonenkov A, Adams AC (2014) Inventing new medicines: the FGF21 story. Mol Metab 3:221-229

Kharitonenkov A, Shiyanova TL, Koester A, Ford AM, Micanovic R, Galbreath EJ, Sandusky GE, Hammond LJ, Moyers JS, Owens RA, Gromada J, Brozinick JT, Hawkins ED, Wroblewski VJ, Li DS, Mehrbod F, Jaskunas SR, Shanafelt AB (2005) FGF-21 as a novel metabolic regulator. J Clin Invest 115:1627-1635

Klaus S, Rudolph B, Dohrmann C, Wehr R (2005) Expression of uncoupling protein 1 in skeletal muscle decreases muscle energy efficiency and affects thermoregulation and substrate oxidation. Physiol Genomics 21:193-200

Kluth O, Mirhashemi F, Scherneck S, Kaiser D, Kluge R, Neschen S, Joost HG, Schurmann A (2011) Dissociation of lipotoxicity and glucotoxicity in a mouse model of obesity associated diabetes: role of forkhead box O1 (FOXO1) in glucose-induced beta cell failure. Diabetologia 54:605-616

Lansang MC, Williams GH, Carroll JS (2001) Correlation between the glucose clamp technique and the homeostasis model assessment in hypertension. Am J Hypertens 14:51-53

Leiter EH, Reifsnyder PC, Flurkey K, Partke HJ, Junger E, Herberg L (1998) NIDDM genes in mice: deleterious synergism by both parental genomes contributes to diabetogenic thresholds. Diabetes 47:1287-1295

Li B, Nolte LA, Ju JS, Han DH, Coleman T, Holloszy JO, Semenkovich CF (2000) Skeletal muscle respiratory uncoupling prevents diet-induced obesity and insulin resistance in mice. Nat Med 6:1115-1120 
Luo Y, McKeehan WL (2013) Stressed Liver and muscle call on adipocytes with FGF21. Front Endocrinol 4:194

Marciniak SJ, Ron D (2006) Endoplasmic reticulum stress signaling in disease. Physiol Rev 86:1133-1149

Montgomery MK, Turner N (2015) Mitochondrial dysfunction and insulin resistance: an update. Endocr Connect 4:R1-R15

Nadeau JH (2001) Modifier genes in mice and humans. Nat Rev Genet 2:165-174

Neschen S, Katterle Y, Richter J, Augustin R, Scherneck S, Mirhashemi F, Schurmann A, Joost HG, Klaus S (2008) Uncoupling protein 1 expression in murine skeletal muscle increases AMPK activation, glucose turnover, and insulin sensitivity in vivo. Physiol Genomics 33:333-340

Noatsch A, Petzke KJ, Millrose MK, Klaus S (2011) Body weight and energy homeostasis was not affected in C57BL/6 mice fed high whey protein or leucine-supplemented low-fat diets. Eur J Nutr 50:479-488

Ohta H, Itoh N (2014) Roles of FGFs as adipokines in adipose tissue development, remodeling, and metabolism. Front Endocrinol 5:18

Ortlepp JR, Kluge R, Giesen K, Plum L, Radke P, Hanrath P, Joost HG (2000) A metabolic syndrome of hypertension, hyperinsulinaemia and hypercholesterolaemia in the New Zealand obese mouse. Eur J Clin Invest 30:195-202

Ost M, Werner F, Dokas J, Klaus S, Voigt A (2014) Activation of AMPKalpha2 is not crucial for mitochondrial uncouplinginduced metabolic effects but required to maintain skeletal muscle integrity. PLoS One 9:e94689

Ost M, Keipert S, van Schothorst EM, Donner V, van der Stelt I, Kipp AP, Petzke KJ, Jove M, Pamplona R, Portero-Otin M, Keijer J, Klaus S (2015) Muscle mitohormesis promotes cellular survival via serine/glycine pathway flux. FASEB J 29:1314-1328

Pan HJ, Agate DS, King BL, Wu MK, Roderick SL, Leiter EH, Cohen DE (2006a) A polymorphism in New Zealand inbred mouse strains that inactivates phosphatidylcholine transfer protein. FEBS Lett 580:5953-5958

Pan HJ, Lin Y, Chen YE, Vance DE, Leiter EH (2006b) Adverse hepatic and cardiac responses to rosiglitazone in a new mouse model of type 2 diabetes: relation to dysregulated phosphatidylcholine metabolism. Vasc Pharmacol 45:65-71

Petrovic N, Walden TB, Shabalina IG, Timmons JA, Cannon B, Nedergaard J (2010) Chronic peroxisome proliferator-activated receptor gamma (PPARgamma) activation of epididymally derived white adipocyte cultures reveals a population of thermogenically competent, UCP1-containing adipocytes molecularly distinct from classic brown adipocytes. J Biol Chem 285:7153-7164

Plum L, Giesen K, Kluge R, Junger E, Linnartz K, Schurmann A, Becker W, Joost HG (2002) Characterisation of the mouse diabetes susceptibility locus Nidd/SJL: islet cell destruction, interaction with the obesity QTL Nob1, and effect of dietary fat. Diabetologia 45:823-830

Poher AL, Altirriba J, Veyrat-Durebex C, Rohner-Jeanrenaud F (2015) Brown adipose tissue activity as a target for the treatment of obesity/insulin resistance. Front Physiol 6:4

Qiu J, Ogus S, Mounzih K, Ewart-Toland A, Chehab FF (2001) Leptin-deficient mice backcrossed to the BALB/cJ genetic background have reduced adiposity, enhanced fertility, normal body temperature, and severe diabetes. Endocrinology 142:3421-3425
Reed DR, Lawler MP, Tordoff MG (2008) Reduced body weight is a common effect of gene knockout in mice. BMC Genet 9:4

Samms RJ, Smith DP, Cheng CC, Antonellis PP, Perfield JW 2nd, Kharitonenkov A, Gimeno RE, Adams AC (2015) Discrete aspects of FGF21 In vivo pharmacology do not require UCP1. Cell Rep 11:991-999

Scherneck S, Nestler M, Vogel H, Bluher M, Block MD, Berriel Diaz M, Herzig S, Schulz N, Teichert M, Tischer S, Al-Hasani H, Kluge R, Schurmann A, Joost HG (2009) Positional cloning of zinc finger domain transcription factor Zfp69, a candidate gene for obesity-associated diabetes contributed by mouse locus Nidd/ SJL. PLoS Genet 5:e1000541

Schulz TJ, Huang TL, Tran TT, Zhang H, Townsend KL, Shadrach JL, Cerletti M, McDougall LE, Giorgadze N, Tchkonia T, Schrier D, Falb D, Kirkland JL, Wagers AJ, Tseng YH (2011) Identification of inducible brown adipocyte progenitors residing in skeletal muscle and white fat. Proc Natl Acad Sci USA 108:143-148

Shabalina IG, Petrovic N, de Jong JM, Kalinovich AV, Cannon B, Nedergaard J (2013) UCP1 in brite/beige adipose tissue mitochondria is functionally thermogenic. Cell Rep 5:1196-1203

Taylor BA, Wnek C, Schroeder D, Phillips SJ (2001) Multiple obesity QTLs identified in an intercross between the NZO (New Zealand obese) and the SM (small) mouse strains. Mamm Genome 12:95-103

Veniant MM, Hale C, Helmering J, Chen MM, Stanislaus S, Busby J, Vonderfecht S, Xu J, Lloyd DJ (2012) FGF21 promotes metabolic homeostasis via white adipose and leptin in mice. PLoS One 7:e40164

Veniant MM, Sivits G, Helmering J, Komorowski R, Lee J, Fan W, Moyer C, Lloyd DJ (2015) Pharmacologic effects of FGF21 Are independent of the "browning" of white adipose tissue. Cell Metab 21:731-738

Vogel H, Nestler M, Ruschendorf F, Block MD, Tischer S, Kluge R, Schurmann A, Joost HG, Scherneck S (2009) Characterization of Nob3, a major quantitative trait locus for obesity and hyperglycemia on mouse chromosome 1. Physiol Genomics 38:226-232

Vogel H, Scherneck S, Kanzleiter T, Benz V, Kluge R, Stadion M, Kryvych S, Bluher M, Kloting N, Joost HG, Schurmann A (2012) Loss of function of Ifi202b by a microdeletion on chromosome 1 of C57BL/6J mice suppresses 11beta-hydroxysteroid dehydrogenase type 1 expression and development of obesity. Hum Mol Genet 21:3845-3857

Vogel H, Montag D, Kanzleiter T, Jonas W, Matzke D, Scherneck S, Chadt A, Tole J, Kluge R, Joost HG, Schurmann A (2013) An interval of the obesity QTL Nob3.38 within a QTL hotspot on chromosome 1 modulates behavioral phenotypes. PLoS One 8:e53025

Voigt A, Ribot J, Sabater AG, Palou A, Bonet ML, Klaus S (2015) Identification of Mest/Peg1 gene expression as a predictive biomarker of adipose tissue expansion sensitive to dietary antiobesity interventions. Genes Nutr 10:477

Zhang Y, Xie Y, Berglund ED, Coate KC, He TT, Katafuchi T, Xiao G, Potthoff MJ, Wei W, Wan Y, Yu RT, Evans RM, Kliewer SA, Mangelsdorf DJ (2012) The starvation hormone, fibroblast growth factor-21, extends lifespan in mice. Elife 1:e00065 